\title{
Simplified Thermo-Mechanical Modeling of Friction Stir Welding with a Sequential FE Method
}

\author{
Hongjun Li and Di Liu
}

\begin{abstract}
This paper presents a methodology for modeling the transient thermal and mechanical responses without computing the heat generated by friction or plastic deformation. The externally applied heat source accounts for the heat generated from tool movement. The novel heat source model includes two parts: surface heat flux at the shoulder-workpiece interface and nodal heat generation in the material that should have been displaced by the tool. The heat source algorithm is described through equations and flow charts. This thermal model was shown to predict a temperature history in good agreement with experimentally measured results. The mechanical interaction between the contacting surfaces was modelled with contact elements. However the analysis failed to converge with the contact pairs active. For the analysis without contact pairs, the predicted longitudinal direction stresses matched well with experiment but the transverse direction stresses were significantly different.
\end{abstract}

Index Terms-Finite element analysis, friction stir welding, thermo-mechanical modeling, sequential method.

\section{INTRODUCTION}

Thermo-mechanical modeling of Friction Stir Welding (FSW) is intended to predict not only the transient temperature field, but also the residual stress and deformations in the work-piece. In the welding process, the movement of the tool generates the heat required to soften the material and cause the material to flow. It is desirable to include the mechanical reaction of the tool but this will induce various challenges in the thermo-mechanical models; such as complex contact behaviour, heat generation from friction and plastic deformation, heat transfer between the tool and plates, temperature and strain rate dependent material model etc. These challenges make the model computationally very expensive [1]-[5]. In a simplified model, often referred to as non-mechanical heat source model, the tool is modelled as a moving heat source. This simplification removes the challenges mentioned above and significantly reduces the complexity of the model, at the expense of lower accuracy.

Simplified, non-mechanical heat source models are widely used, especially in the industrial field. For example, Engineers in the Hitachi Company used a simplified model to estimate the residual stress and structural deformation of a double-skinned train body component welded by FSW [6].

Manuscript received May 2, 2014; revised July 17, 2014. This work was supported by SRF for ROCS, State Education Ministry of China, 2013, and Science Foundation of Zhejiang Sci-Tech University (grant number 1103811-Y)

The all authors are with the Zhejiang Sci-Tech University, Hangzhou, 310018 China (e-mail: lihongjun@zstu.edu.cn).
Common to those models is the prescribed non-mechanical heat input.

Zhu and Chao [7] presented a sequentially coupled thermo-mechanical model using WELDSIM, an FE code developed by the authors. An inverse analysis method was used for thermal analysis based on experimentally measured temperatures. It was assumed that the heat flux was linearly distributed on the top surface of the plate and the heat generated at the tool pin was neglected. In subsequent mechanical analysis, the forces from the tool were not considered. The effect of fixture release when the weld cooled down to room temperature was studied. Comparison of numerical residual stress fields with the measured values by the neutron diffraction technique at several specific locations showed good agreement.

Chen and Kovacevic [8], [9] proposed a three-dimensional FE model to study the thermo-mechanical process in the butt-welding of aluminium alloy 6061-T6. The heat generation caused by the friction was calculated using experimentally measured contact pressure and a constant value of the friction coefficient. The temperature datum at each time increment was used to evaluate the mechanical and thermal properties. The mechanical effect of the shoulder was considered assuming a Coulomb friction law for the interaction between the shoulder and the material.

Soundararajan et al., [10] refined the FE models in [8], [9] by applying an adaptive contact conductance at the interface of shoulder-workpiece. At the beginning of the FE thermo-mechanical analysis, a uniform contact conductance was used to predict the stress at the interface. This pressure distribution contours were applied to define the non-uniform pressure denpendent contact conductance in the thermal model, estimating the temperature profiles. It was concluded that the model with adaptive contact conductance could provide more accurate thermal and residual stress results by comparing with experimental values. The above simplified models didn't include the contact pressure dependent heat transfer coefficient in their boundary condition definitions. Although Soundararajan et al., [10] considered this; the calculated non-uniform contact conductance at the beginning of the analayis was kept constant and used throughout the whole welding process.

In this paper, a methodology for modeling the transient thermal and mechanical responses is presented. A new adaptive non-uniform convective boundary condition is also proposed here to accurately model the temperature evolution during FSW process.

\section{MODEL DESCRIPTION}

All simplified models were created in ANSYS Version 10.0 [11]. In a sequential thermal-stress analysis, a nonlinear 
transient thermal analysis is performed first, and then the nodal temperatures from any load step or time point in the thermal analysis are read in and applied as loads for the subsequent stress analysis.

\section{A. Heat Transfer Model}

In FSW, the amount of heat input and output to the system is not yet well understood. A substantial effort is usually needed to determine how much heat flows into the tool and how much to the plates. This is highly dependent on the changing friction coefficient, downward force, temperature and the tribology conditions of the contacting surfaces [12]. For simplified models, it is essential to know this and to apply the corresponding heat input to the FE model. The inverse method determines heat input conditions by varying estimated values. The best match with measured temperatures is used in the model. Here the torque approach is implemented in the model. The heat input is correlated with experimental torque results measured from the rotating spindle, eliminating part of the matching process.

The total weld power is the product of toque and angular velocity:

$$
P_{a v}=M_{t o q} \omega
$$

The process efficiency is defined as the percentage of the average power input into the workpiece in the total weld power,

$$
P_{w}=\eta_{F S W} P_{a v}
$$

It is assumed that a uniform contact pressure exists at the interface between the shoulder and the workpiece and all the heat generated comes from friction. Hence heat flux is linearly distributed in the radial direction and in proportion to the distance from the tool.

$$
q_{s}(r)=\frac{3 P_{w s} r}{2 \pi\left(R_{\text {shoulder }}^{3}-R_{\text {pin }}^{3}\right)} \text { for } \quad R_{\text {pin }} \leq r \leq R_{\text {shoulder }}
$$

The heat generated by tool pin is applied to the FE model in the format of nodal volumetric heat generation rate. In the plunge period, no heat flux is applied to the shoulder-workpiece surface until the end of this stage. The nodal volumetric heat generate rate is calculated by dividing the tool pin's heat contribution by its volume, mathematically expressed as

$$
q_{\text {pin }}=\frac{P_{w}}{\pi R_{p i n}^{2} H_{p i n}\left(1+f_{\text {shoulder } / \text { pin }}\right)}
$$

The number of nodes generating heat increases proportionally with plunge speed. During the dwell stage, both the surface heat flux and nodal volumetric heat generation are applied to the model. After a specified time the heat source then moves along the joint line. When the tool comes to the end of the traverse stage, the surface heat load is deleted and the number of nodes generating heat starts to decrease. There is no force applied at the interface and no heat will be generated during the pull out period. A flow chart of applied heat source is shown in Fig. 1(a)-Fig. 1(c) for the entire process. An algorithm was created using the ANSYS APDL Macro language to incorporate this flow chart into the model input file.

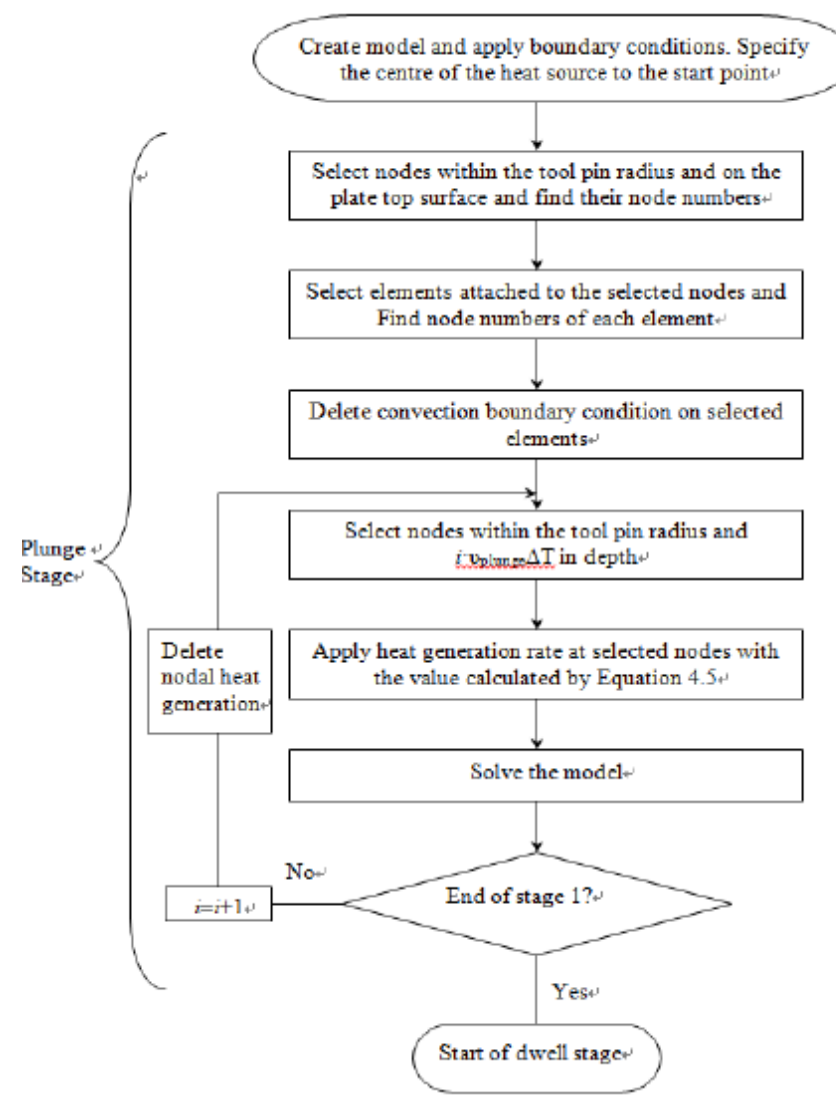

Fig. 1(a). FE model flow chart of the plunge stage.

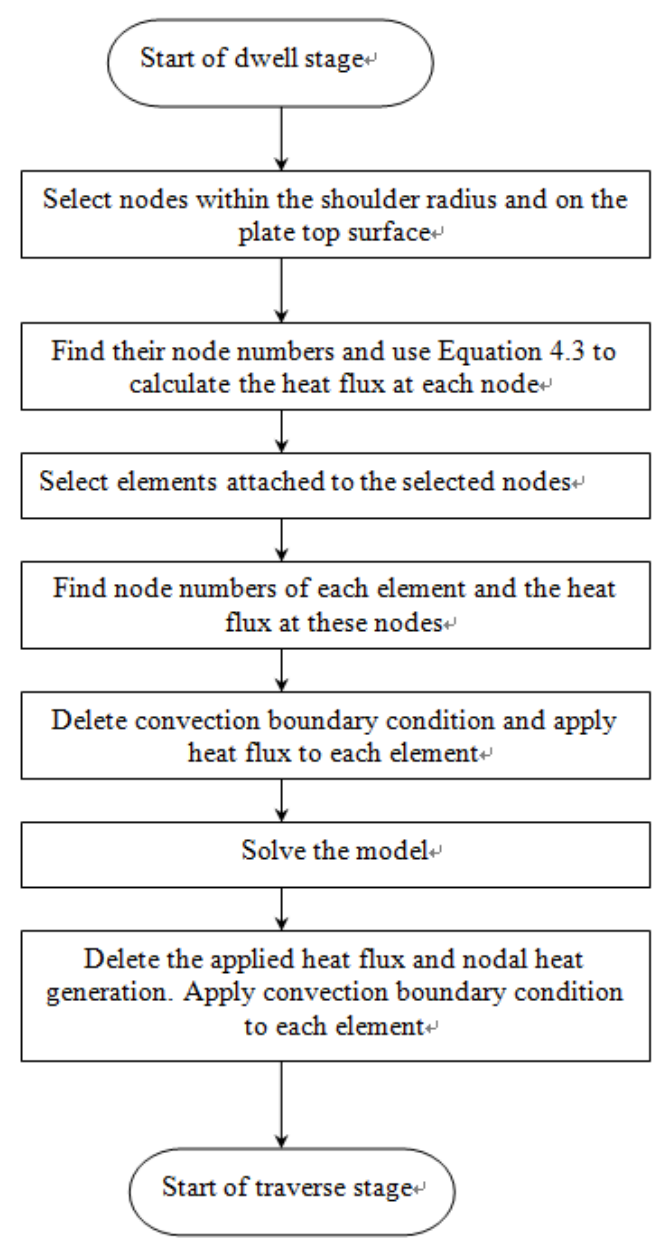

Fig. 1 (b). FE model flow chart of the dwell stage. 
The heat transfer model uses the 3-D solid element SOLID70, which has eight nodes each with a single temperature degree of freedom. The boundary conditions for thermal analysis are illustrated in Fig. 4 Convection boundary conditions with film coefficient $\mathrm{h} 1$ are specified for workpiece surfaces which are exposed to the air. The radiation heat transfer of the surfaces is lumped into the convection, as it is reportedly small [12]. The conduction heat exchange between the bottom surface of the workpiece and the backing plate is simplified by using a larger convective coefficient. This is due to the lack of gap conductivity data and the difficulty to obtain an accurate value. The gap conductance is highly dependent on the welding conditions, such as material, contact pressure and temperature. Thus the complexity of gap conductance is circumvented by assigning a convection boundary condition.

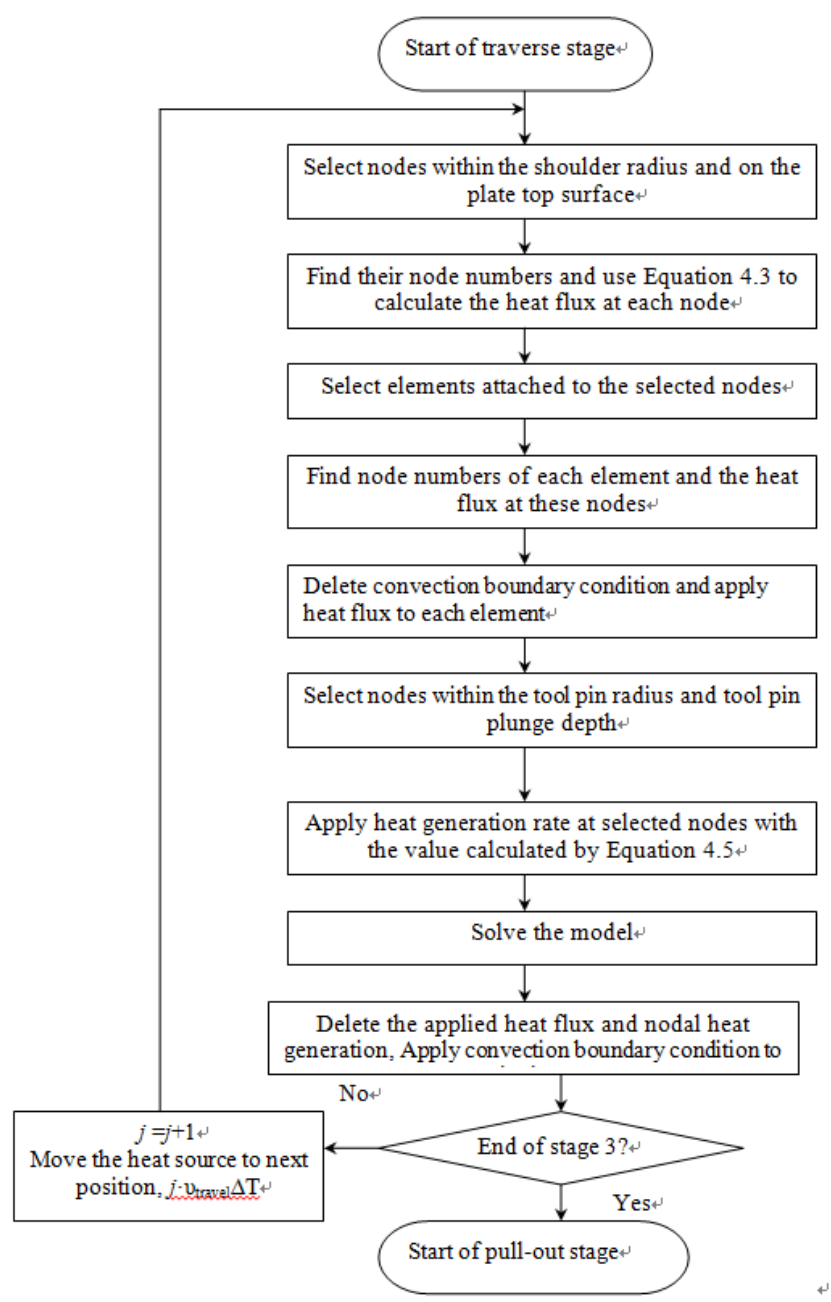

Fig. 1(c). FE model flow chart of the traverse stage.

\section{B. Mechanical Model}

The thermal model is converted to a mechanical model for subsequently thermo-mechanical analysis by changing the element type to SOLID45 while maintaining the same mesh and load step size. After the completion of thermal analysis, the temperature results are imported to the mechanical model. Thus the thermal strain and thermal stress are produced in the workpiece, causing deformation and distortion of the plates.

The elastic-perfect plastic material model was adopted to characterise the stress-strain relationship. The material plastic deformation is assumed to obey the von Mises yield criterion and associated flow rule. Like the temperature dependent conductivity and specific heat used in thermal model, the temperature dependence of the material yield strength is incorporated in the mechanical model.

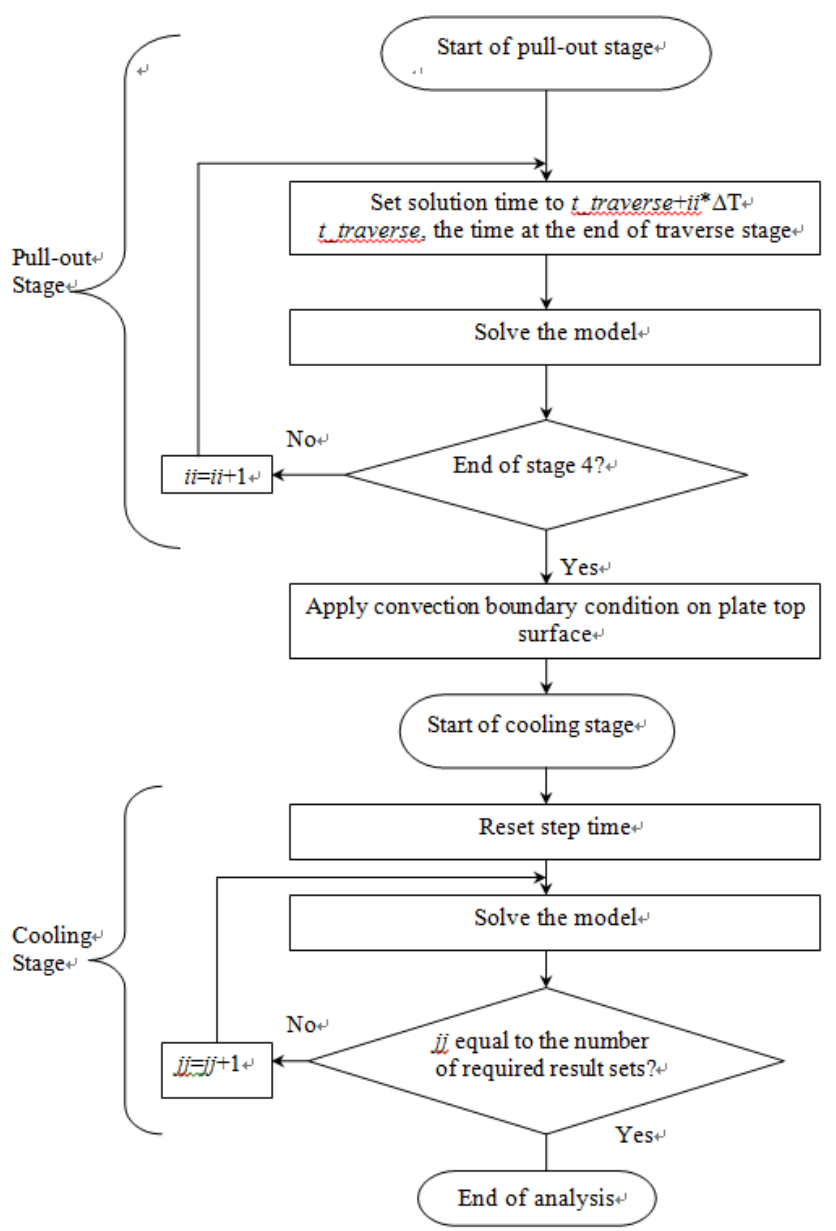

Fig. 1(d). FE model flow chart of the pull-out and cooling stages.

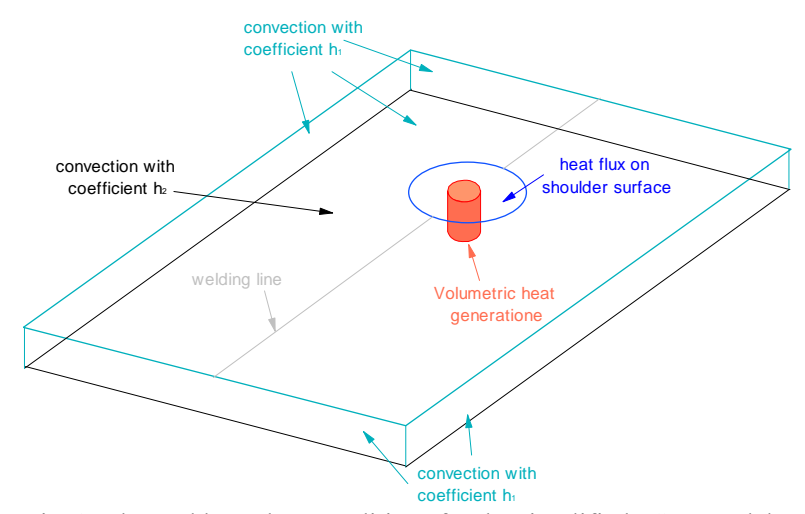

Fig. 2. Thermal boundary conditions for the simplified FSW Models.

To simulate the mechanical action of the tool on the workpiece, including friction and downward force, a contact pair is established, with the contact-target elements CONTA173 and TARGET170 used on the workpiece top surface and tool bottom surface. The tool was assumed to be cylindrical without the pin and the tool bottom surface circular, with the radius Rshoulder. A pilot node is created to control the movement of the Target Elements, i.e. the tool. Similar contact pairs are constructed at the 
workpiece-backing plate interface. The workpiece is clamped by applying the displacement constraints based on the experimental setup (see Fig. 2).

In the plunge stage, the downward force applied to the pilot node of the tool increases from zero to the maximum value, while the tool keeps rotating at a constant speed. In the dwell stage, both the force and rotating speed remains unchanged. The displacement degree of freedom of the pilot node in the joining direction is activated and the tool moves at the welding speed once the welding phase starts. During the whole process the workpiece is constrained and fixed. When the tool has covered the specified welding distance, the contact pair at the tool-workpiece interface separates as the tool is lifted and pulled out from the workpiece. The rotation of the tool then has no effect on the workpiece, so the rotating speed can be set to zero at the start of the pull out phase. It should be noted that the same step size as in the thermal model mush be used in the mechanical model.

\section{Material Properties}

Aluminum 6061-T6 has excellent joining characteristics with relatively high strength and good workability. It is frequently used in aerospace industry, particularly for aircraft fittings. The temperature varying thermal and mechanical material properties are presented in Table I. The remaining material properties used in the model are given in Table II. The melting point of $\mathrm{Al} 6061$ is in the range $582-652{ }^{\circ} \mathrm{C}$.

TABLE 1: TEMPERATURE DEPENDENT MATERIAL PROPERTIES OF 6061-T6.

\begin{tabular}{lll}
\hline \hline $\begin{array}{l}\text { TEMPERATURE } \\
\left({ }^{\circ} \mathrm{C}\right)\end{array}$ & $\begin{array}{l}\text { SPECIFIC HEAT } \\
\left(\mathrm{J} / \mathrm{KG}^{\mathrm{o}} \mathrm{K}\right)\end{array}$ & $\begin{array}{l}\text { YIELD STRESS } \\
(\mathrm{MPA})\end{array}$ \\
\hline 0 & 910 & 280 \\
40 & 950 & 275 \\
125 & 1000 & 270 \\
225 & 1050 & 220 \\
325 & 1100 & 70 \\
425 & 1150 & 20 \\
575 & 1270 & 0 \\
645 & 1310 & 0 \\
\hline \hline
\end{tabular}

TABLE II: TEMPERATURE INDEPENDENT MATERIAL PROPERTIES OF AL6061

\begin{tabular}{lllll}
\hline \hline $\begin{array}{l}\text { Young's } \\
\text { Modulus } \\
(\mathrm{GPa})\end{array}$ & $\begin{array}{l}\text { Poisson's } \\
\text { Ratio }\end{array}$ & $\begin{array}{l}\text { Thermal } \\
\text { Expansion } \\
\text { coefficient } \\
\left(10^{-6} / \mathrm{K}\right)\end{array}$ & $\begin{array}{l}\text { Thermal } \\
\text { conductivity } \\
\left(\text { Watt } / \mathrm{m}^{\circ} \mathrm{K}\right)\end{array}$ & $\begin{array}{l}\text { Density } \\
\left(\mathrm{Kg} / \mathrm{m}^{3}\right)\end{array}$ \\
\hline 68.9 & 0.33 & 25 & 167 & 2700 \\
\hline \hline
\end{tabular}

\section{Welding Configurations}

The welding configurations in the experimental work [8] are used here with the aim of verifying the computed residual stresses. Each plate to be butt welded has a length of $24 \mathrm{~cm}$, a width of $5 \mathrm{~cm}$ and a thickness of $6 \mathrm{~mm}$. The tool shoulder radius is $12 \mathrm{~mm}$ and the pin radius is $3 \mathrm{~mm}$. The height of the pin was not given in the paper; a value of $6 \mathrm{~mm}$ was used. Chen et al., [8] did not provide any information on the plunge and dwell stages. The present model assumes a plunge speed of $0.2 \mathrm{~mm} / \mathrm{s}$, usually used for aluminium alloys. The tool rotating and travelling velocities are set to $500 \mathrm{rpm}$ and 140 $\mathrm{mm} / \mathrm{min}$, respectively.

\section{THERMAL ANALYSIS}

A total heat input of $2134 \mathrm{~J}$ into the workpiece was chosen. $220 \mathrm{~J}$ was applied through nodal volumetric heat generation and $1914 \mathrm{~J}$ through surface heat flux. Fig. 3 shows both predicted and measured temperature histories at the location $10 \mathrm{~mm}$ to the weld centerline and $1.6 \mathrm{~mm}$ below the top surface of the plate. An excellent match between the two curves was obtained. The stress analysis was then carried out with the temperature results from the thermal analysis.

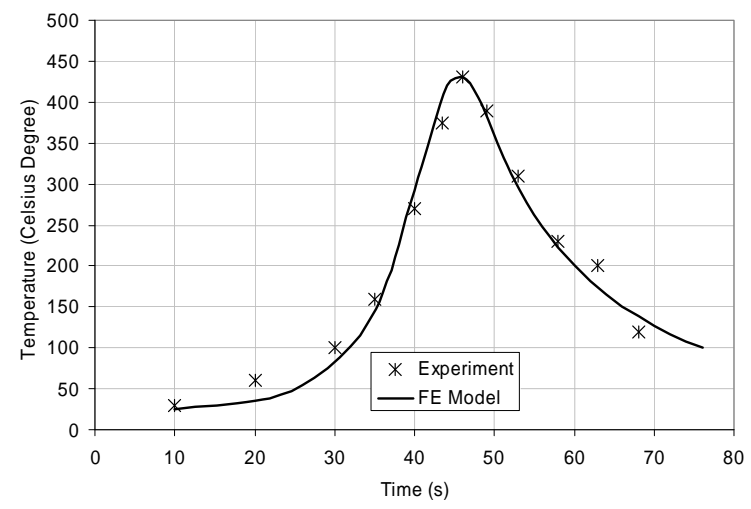

Fig. 3. Comparison of the numerical and the measured temperature histories at a point $10 \mathrm{~mm}$ from the joining line and $1.6 \mathrm{~mm}$ below the top surface, $\mathrm{Al}$ 6061 .

\section{STRESS ANALYSIS}

The solution could not converge during the analysis as a result of the incorporated two contact pairs, especially in dwell and traverse states. Fig. 4 (b) \& Fig. 4 (c) shows the deformed mesh and corresponding stress distribution at a time in the plunge stage. A displacement scale factor of 200 was used to amplify the deformed plate shape, but it had no effect on the rigid tool and backing plate. The greatest deformation occurred at the plate where the heat flux and nodal volumetric heat generation were applied. This was caused by the high temperature and temperature gradient at this region, as thermal strain is directly linked to the temperature changes. The reason that the solution was not converged mainly came from the large local deformation and abrupt separation of contacting elements. One of the typical errors was "Contact element 10053 (real ID 3) status changes abruptly from no-contact -> contact (with target element 9374)".

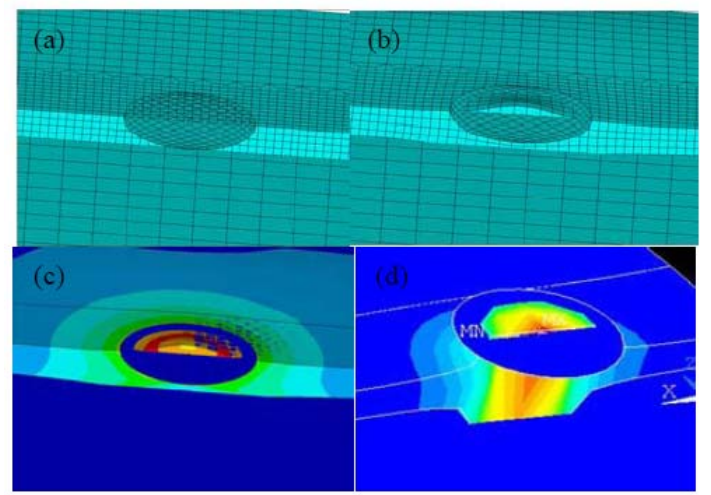

Fig. 4. Mesh and stress plot for simplified Al 6061 model (a) undeformed mesh, (b) deformed mesh, (c) a stress plot during plunging stage and (d) a temperature plot at the dwell stage. 
The lack of convergence could be further explained in picture (d) in Fig. 4, an exaggerated temperature distribution on a deformed plate shape during the dwell stage. The high temperature is concentrated in the workpiece under the tool, causing significant high thermal expansion and deformation. When the applied heat source moves forward along the welding line, the material ahead of the tool will also experience a large deformation and complex residual stress field forms in the material behind the tool. Under such circumstances an error "Sudden change in contact status of an element" is issued. This makes the convergence difficult and finally terminates the analysis.

To avoid this convergence problem, the contact pairs were suppressed in the stress analysis, as the thermal stress accounts for the major part of the total stress built up during the FSW process [10], [13]. Moreover, this simplification does not impair the characteristics of the heat input source model used in the thermo-mechanical analysis. However another convergence problem turned up when the fixture was released. The predicted stresses in $\mathrm{X}$ (longitudinal) and $\mathrm{Z}$ (transverse) directions at $117.2 \mathrm{~s}$ just before the fixture release were compared with the measured residual stresses, M-Sx and M-Sy, shown in Fig. 5.

The stresses in $\mathrm{Z}$ direction are very close to the measured ones but there is a large discrepancy in the stresses in $\mathrm{X}$ direction, although the overall trend is similar. This may be because the workpiece is still in a fixed state.

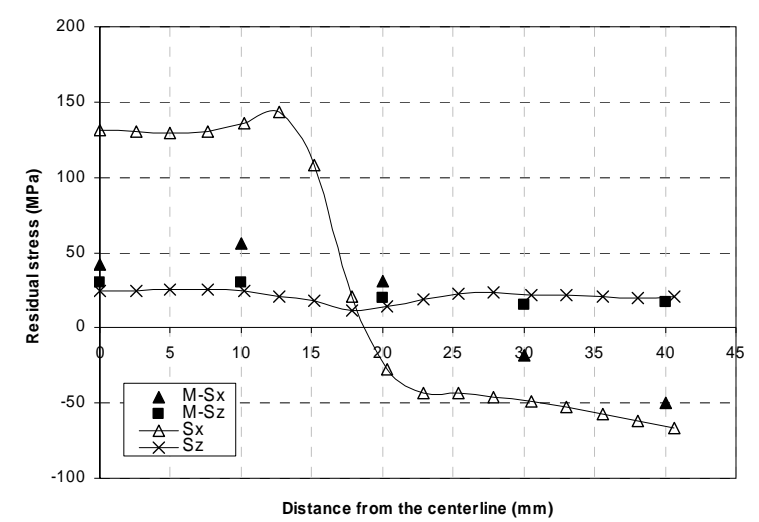

Fig. 5. Stresses on the top surface and at the mid-plane of the Al6061 workpiece.

\section{AN ADAPTIVE CONVECTIVE BOUNDARY CONDITION ALGORITHM}

In the FSW process, a backing plate is required to support the workpiece. A considerable amount of heat is lost through this contact interface. Backing plates with different conductivities can influence the temperature evolution across the workpiece and finally the quality of the weld. A faulty weld may be produced if too much heat is lost to the backing plate [14]. Hence it is necessary to consider the heat transfer at the workpiece-backing plate interface.

The predominant mode of heat transfer at the contact interface is contact conduction. Thermal contact conductance is defined as the ratio of heat flux across the joint to the additional temperature drop as a result of the imperfect contact at the interface [15]. It is affected by many factors such as contact pressure, interstitial materials, surface roughness and flatness. During FSW, the contact region immediately below the tool has the highest contact pressure, causing the highest contact conductance. In some other parts of the contact surface, a small gap may be created due to lack of clamping, leading to a much smaller contact conductance (also called a gas gap conductance). Therefore, to make the model more robust, the variant non-uniform contact conductance should be taken into account.

In all the previous numerical FSW models in the literature, the conductive heat loss through the backing plate is simulated by applying a large average convective heat transfer coefficient to the bottom surface of the workpiece. Furthermore, most of the models assumed a constant convective coefficient on the whole surface. Only one recently work by Soundararajan et al., [10] used a contact pressure dependent heat transfer coefficient. An initial thermo-mechanical analysis with a uniform contact conductance value was performed to determine the stress at the workpiece-backing plate. According to the stress distribution contours, the bottom surface of the workpiece was divided into eight parts, each of which was assigned a constant convective heat transfer coefficient. This thermal boundary condition was then used to predict the thermal history in the workpiece. It should be noted that the determined convective coefficient pattern at the beginning of the analysis was used and kept unchanged throughout the subsequent thermal analysis. Due to the different contact conditions at different stages of the process, the unchanged thermal boundary condition is not appropriate.

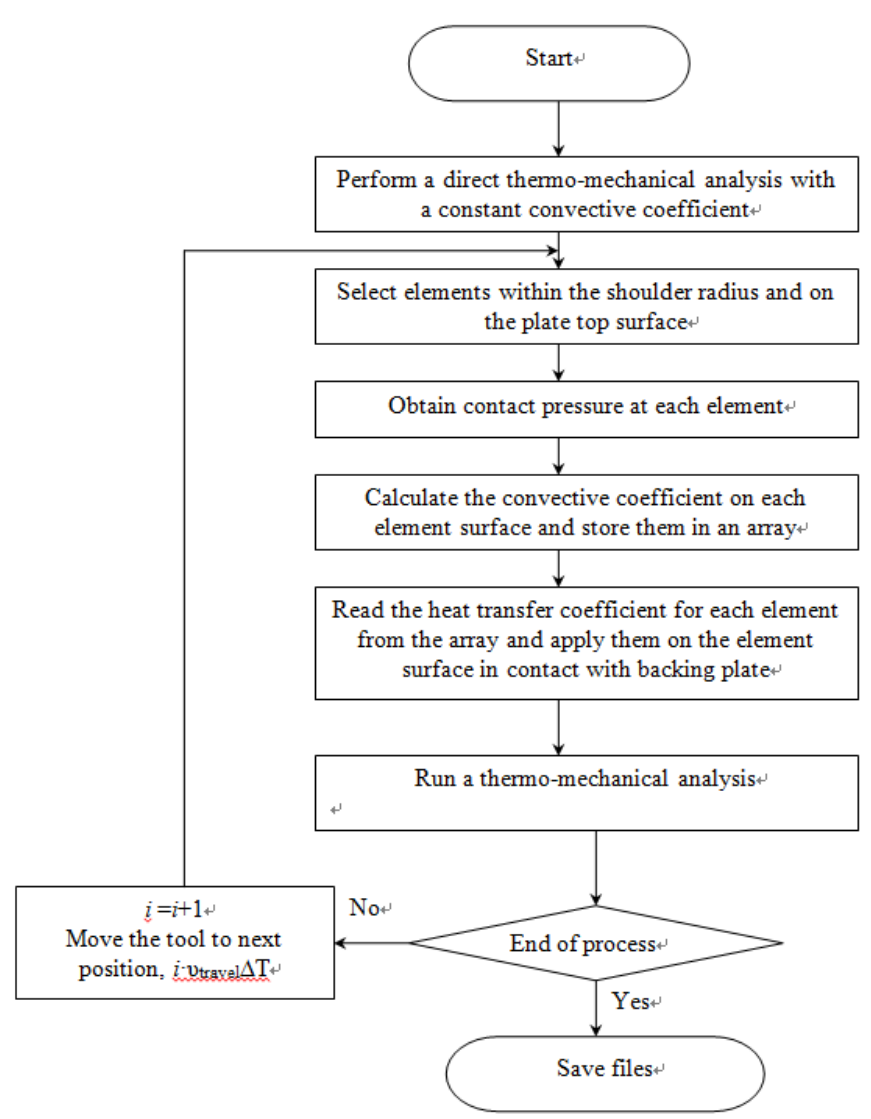

Fig. 6. An adaptive convective boundary condition algorithm for bottom surface of the workpiece.

A new adaptive non-uniform convective boundary 
condition is proposed here, in which the contact conductance matches the stress distribution and evolves with the development of the contact pressure. At the beginning of the analysis a constant convective value is used to obtain the contact pressure at the contact interface. Then the convective film which is obtained according to the contact pressure at each element is applied to the element surfaces facing the backing plate for the thermo-mechanical analysis at next time increment. At the end of each analysis (time step) the contact pressure is extracted until the end of the welding process. This procedure is simply illustrated in Fig. 6.

An example contour plot of convection coefficient applied at the bottom surface of the workpiece is presented in Fig. 7 (ignore the blue element edge). Fig. 7 (a) shows the thermal boundary condition at the beginning of traverse stage and (b) when the tool moves to about half length of the plate. The contact conductance data, i.e. the relationship between the contact pressure /contact gap and heat transfer coefficient, was recruited from Rohsenow et al., [16]. A significant discrepancy in convection coefficient was predicted. Contact gap existed in the blue-colored region and a much lower convection coefficient value was applied to it.
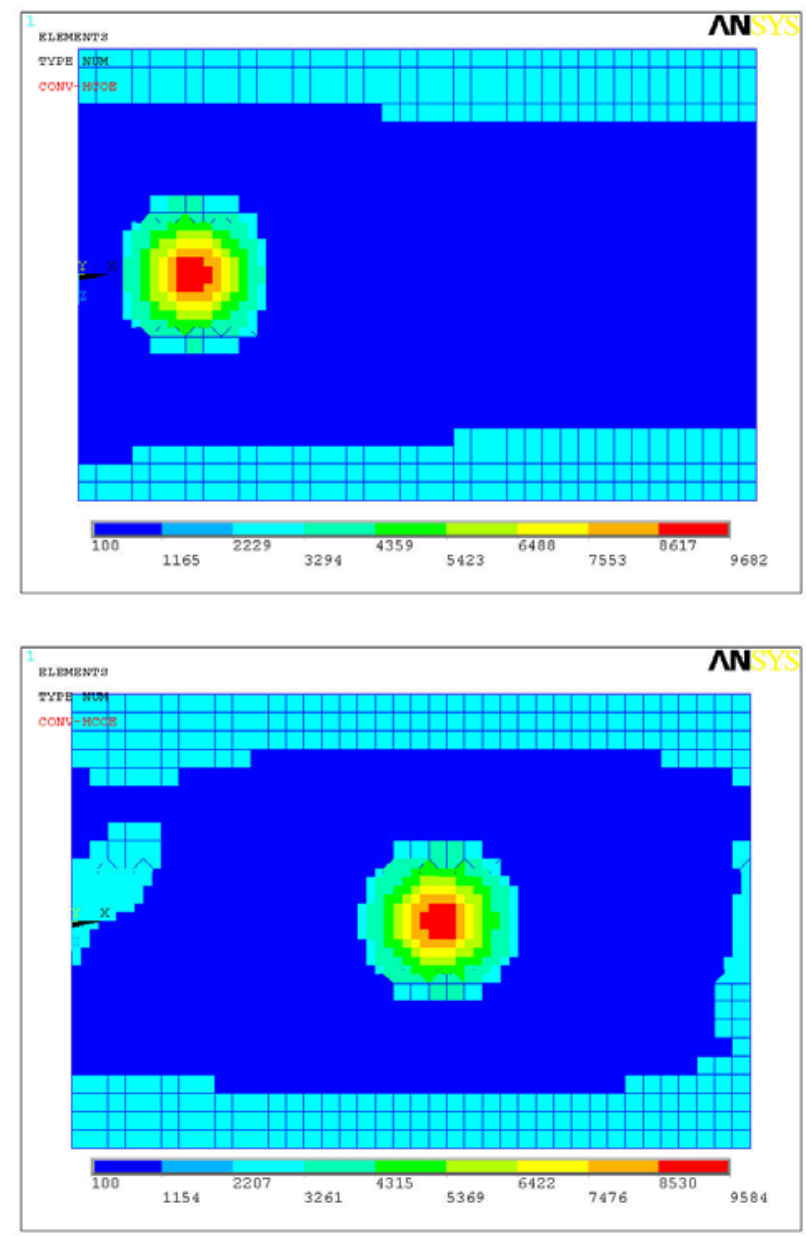

Fig. 7. Examples of adaptive convective boundary conditions.

\section{CONCLUSION}

In a FSW process, the heat is produced by interactions between the tool and workpiece and there is no other direct external heat input into the plates. The simplified thermo-mechanical models are not coupled-field models and not used to investigate the fundamental mechanisms related to the welding formation process, but aims to predict the transient temperature and stress evolution in the welding process, particularly the residual stress.

A methodology for modeling the transient thermal and mechanical responses is presented in this paper. The externally applied heat source accounts for the heat generated from tool movement. The novel heat source model includes two parts: surface heat flux at the shoulder-workpiece interface and nodal heat generation in the material that should have been displaced by the tool. This thermal model was validated by comparing with measured results and a good agreement was found. The mechanical analysis encountered a convergence problem caused by contact pairs. For the analysis without contact pairs, the predicted longitudinal direction stresses matched well with experiment but the transverse direction stresses were significantly different.

The contact pressure and temperature dependent heat transfer coefficient significantly affect the thermal analysis. It was found that the proposed adaptive convective boundary condition algorithm is well suited to represent the varying thermal contact conductance at the backing plate-workpiece interface.

\section{REFERENCES}

[1] X. He, F. Gu, and A. Ball, "A review of numerical analysis of friction stir welding," Progress in Materials Science, vol. 65, pp.1-66, 2014.

[2] R. Hamilton, D. Mackenzie, and H. Li, "Multi-Physics simulation of friction stir welding process," Engineering Computation-International Journal for Computer-Aided Engineering and Software, vol. 27, pp. 967-985, 2010.

[3] F. A. Badour, N. Merah, A. Shuaib, and A. Bazoune, "Coupled eulerian lagrangian finite element modeling of friction stir welding processes," Journal of Materials Processing Technology, vol. 213, pp. 1433-1439. 2013.

[4] E. Feulvarch, J. C. Roux, J. M. Bergheau, "A simple and robust moving mesh technique for the finite element simulation of Friction Stir Welding," Journal of Computational and Applied Mathematics, vol. 246, pp. 269-277, 2013.

[5] M. Chiumenti, M. Cervera, C. A. D. Saracibar, and N. Dialami, "Numerical modeling of friction stir welding processes," Computer Methods in Applied Mechanics and Engineering, vol. 254, pp. 353-369, 2013.

[6] T. Kawasaki, T. Makino, K. Masai, H. Ohba, Y. Ina, and M. Ezumi, "Application of friction stir welding to construction of railway vehicles," JSME International Journal, Series A, vol. 47, no. 3, 2004

[7] X. K. Zhu and Y. J. Chao, "Numerical simulation of transient temperature and residual stresses in friction stir welding of $304 \mathrm{~L}$ stainless steel," Journal of Materials Processing Technology, vol. 146, pp. 263-272, 2004.

[8] C. M. Chen and R. Kovacevic, "Finite element modeling of friction Stir Welding-Thermal and Thermomechanical analysis," International Journal of Machine Tools and Manufacture, vol. 43, pp. 1319-1326, 2003.

[9] C. M. Chen and R. Kovacevic, 'Thermo mechanical modeling and force analysis of friction stir welding by the finite element method," in Proc. the IMECH E Part C Journal of Mechanical Engineering Science, vol. 218, pp. 509-519, 2004.

[10] V. Soundararajan, S. Zekovic, and R. Kovacevic, 'Thermo-mechanical model with adaptive boundary conditions for friction stir welding of $\mathrm{Al}$ 6061," International Journal of Machine Tools and Manufacture, vol. 45, no. 14, pp. 1577-1587, 2005.

[11] ANSYS 10.0 Documentation, ANSYS Inc. 2005

[12] Y. J. Chao, X. Qi, and W. Tang, "Heat transfer in friction stir welding-experimental and numerical studies," Journal of Manufacturing Science and Engineering, vol. 125, pp. 138-145, 2003

[13] M. Z. H. Khandkar, J. A. Khan, A. P. Reynolds, and M. A. Sutton, "Predicting residual thermal stresses in friction stir welded metals," Journal of Materials Processing Technology, Volume, vol. 174, pp. 195-203, 2006 
[14] C. Conner, "Feasibility study and initial design of a friction stir welding rig," Undergraduate Thesis, University of Strathclyde, 2006.

[15] S. M. S. Wahid and C. V. Madhusudana, "Gap conductance in contact heat transfer," International Journal of Heat and Mass Transfer, vol. 43, pp. 4483-4487, 2000

[16] W. M. Rohsenow, J. P. Hartnett, and E. N. Ganic, Handbook of Heat Transfer Fundamentals, Second Edition, McGraw-Hill, pp. 4-19, 1985

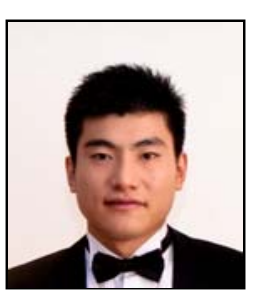

Hongjun Li was born in July 1981 in Shandong, China. He received the $\mathrm{PhD}$ degree in mechanical engineering from University of Strathclyde, UK, 2008. His research is focused on finite element method application in FSW/FSP processes.

$\mathrm{He}$ is an associate professor and the deputy head of Department of Mechanical Design and Manufacture at Zhejiang Sci-Tech University. His research is focused on finite element method application in FSW/P and has published several papers on the simulation of FSW, one of which was noted as "the most practical, advanced modeling method for FSW reported to date."

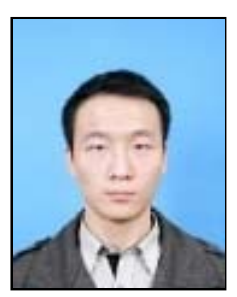

Di Liu was born in Henan, 1992, China. He received B.Eng degree in material processing and control engineering form Henan Polytechnic University, China, 2014. He is currently studying towards M.Eng degree at Faculty of Mechanical Engineering and Automation, Zhejiang Sci-Tech University. His research interests include forging, friction stir welding and processing of metallic materials. 